\title{
The Challenge of Efficient Synthesis of Biofuels from Lignocellulose for Future Renewable Transportation Fuels
}

\author{
Päivi Mäki-Arvela, ${ }^{1}$ Eero Salminen, ${ }^{1}$ Toni Riittonen, ${ }^{1}$ Pasi Virtanen, ${ }^{1}$ \\ Narendra Kumar, ${ }^{1}$ and Jyri-Pekka Mikkola ${ }^{1,2}$ \\ ${ }^{1}$ Laboratory of Industrial Chemistry and Reaction Engineering, Process Chemistry Centre, Åbo Akademi University, \\ 20500 Åbo-Turku, Finland \\ ${ }^{2}$ Technical Chemistry, Department of Chemistry, Chemical-Biological Center, Umeå University, 90187 Umeå, Sweden
}

Correspondence should be addressed to Päivi Mäki-Arvela, pmakiarv@abo.fi

Received 22 June 2011; Revised 21 September 2011; Accepted 6 October 2011

Academic Editor: David Kubička

Copyright ( 2012 Päivi Mäki-Arvela et al. This is an open access article distributed under the Creative Commons Attribution License, which permits unrestricted use, distribution, and reproduction in any medium, provided the original work is properly cited.

\begin{abstract}
Dehydration of sugars to 5-hydroxymethylfurfural (HMF) has recently been under intensive study by a multitude of research groups. On the other hand, when lignocellulosic biomass is applied as the starting material, very few studies can be found in the open literature. The direct synthesis of HMF, in line with the idea of "one-pot" synthesis strategy from lignocellulose, is demanding since the overall process should encompass dissolution, hydrolysis, and dehydration steps in a single processing unit. Ionic liquidassisted methods to produce hydroxymethyl-furfural directly from lignocellulosic biomass are reported here together with a short overview of the most important biofuels. In reality, HMF is not suitable to be used as a single-component fuel as such, and, consequently, methods to produce HMF derivatives suitable as liquid fuels are reported.
\end{abstract}

\section{Introduction}

The demand for renewable energy is expected to significantly increase from current levels, partially due to the depletion of fossil fuels and, also, as a result of political decisions aiming at reduced dependency on fossil resources. Among other actors, European Union (EU) has announced an ambitious goal of reaching $20 \%$ renewable energy share by 2020 [1]. In fact, the focus on the use of renewable energy is at low carbon-footprint fuels, resulting in reduced emissions of greenhouse gases to countermeasure the ever-increasing global use of fossil fuels affecting our biosphere [2]. Different sources of renewable energy such as utilization of wind and solar power, hydroelectric installations, and geothermal energy are used today. The use of biomass resources, either for direct combustion (including thermal processes such as gasification and pyrolysis) or as a source of raw material for various biological processes (fermentations; enzymatic transformation; anaerobic bacterial biogas production), as well as chemical and catalytic processes exist that aim at liquid or gaseous products. Transport sector stands for approximately one-third of the world's primary energy-consumption currently amounting to about 500 EJ [3]. Since, for example, electric cars are not ideal for long distance transportation due to the low energy capacity of even the best batteries of today, there is a strong need to develop new liquid transportation fuel mixes. Upon formulation of renewable fuels from biomass, a general central step is to reduce the oxygen content embedded in the molecular structure of any biomass. Various liquid biofuels were already used in the beginning of the era of internal combustion engines (like vegetable oil in the Diesel and alcohols in the Otto engines) $[4,5]$. More recently, a lot of varieties have been introduced. In order to mention a few, ethanol in various blends with gasoline; biodiesel, composed of fatty acid methyl or ethyl esters (FAME, FAEE) produced from triglycerides and oils; renewable diesel fuels stemming from hydrotreatment or catalytic deoxygenation of fatty acids and their derivatives, are representative examples. In addition, various esters and ethers from biomass have been synthesized. More recently, 
the Swedish oil company Preem AB [6] introduced in collaboration with another Swedish company, Sunpine AB [7], a process where Tall oil (a residue from chemical pulping) is refined to a synthetic, renewable "green diesel" to be blended with its conventional, fossil counterpart. Also, the Finnish Neste Oil introduced a few years ago the NExBTL, synthetic diesel that can be prepared from any oils and fats. Currently the company is running its third refinery based on this concept in Rotterdam, Netherlands [8]. The critical fuel properties of many biofuels (e.g., boiling point, corrosivity, water miscibility, viscosity, and freezing point) are very different. Since these properties determine the engine performance, engine alterations are usually required.

The earlier processes to obtain upgraded (bio)fuels generally involve the use of homogeneous, heterogeneous, or biological (enzymes, microorganisms, and yeasts) catalysts, such as strong mineral acids, solid acids, or altered bakers yeasts which are summarized in [9]. Each and every one of these processes has its pros and cons in terms of separation issues, corrosivity, recyclability, and cost of operations. Therefore, new solutions are needed.

Ionic liquids are promising solvents for lignocellulosic biomass (e.g., wood) capable of dissolving cellulose and other biomass components [10]. Interesting research efforts are ongoing to produce, not only sugars, but also HMF directly from lignocellulose [11-13]. Ionic liquid-assisted dehydration of sugars and carbohydrates has been of high interest during recent years and one review article covering this topic can be found in [14]. The efforts have mainly been concentrating on the use of sugars and carbohydrates as starting materials. However, only few reports can be found on dehydration of lignocellulose with ionic liquids $[11-13,15]$. The process concepts involve several steps (dissolution, hydrolysis, isomerization, and dehydration) although it would be beneficial to use only one reactor vessel for the entire transformation train.

The philosophy of one-pot synthesis is to perform consecutive reaction steps in a single-reactor unit. Consequently, resources and costs can be saved in the form of energy, equipment, and apparatus as well as solvents. Also, separation of each and every intermediate can thus be avoided [16]. The challenge is, naturally, to determine the optimum reaction conditions that facilitate the combination of several reactions. Dehydration of glucose and lignocellulosic material serves as an example of one-pot synthesis, since in the former, glucose should first be isomerized followed by dehydration of fructose. The latter includes additionally, dissolution of cellulose, hemicelluloses, and lignin, followed by saccharification of cellulose and hemicelluloses to sugars. In all steps, ionic liquids can serve as the solvent or cosolvent. Furthermore, upon use of, for example, acidic ionic liquids, the solvent also acts as a hydrolyzing catalyst [17]. In fact, sugar transformations for 5-hydroxymethyl furfural (HMF) esters and ethers have been demonstrated in (acidic) ionic liquids containing $\mathrm{CrCl}_{2}$ that gives rise to the species responsible for the catalytic acidity [18]. Recently, a novel system was introduced where the undesired chromium was replaced by boron compounds [19].
Research in the field of ionic liquid as a reaction media and as supported ionic liquid catalysts (SILCAs) for reactions of fine chemical synthesis has been carried out by the research group. A new family of hydrophobic ionic liquid based on aliquat 336 (tricaprylmethylammonium chloride) was synthesized. Ionic liquids were further applied in preparation of SILCAs with Pd metal particles and applied in the hydrogenation of citral. The main products obtained during the hydrogenation reaction were citronellal and dihydrocitronellal [20]. The applicability of the SILCAs in continuous hydrogenation of citral has also been proven [21]. Furthermore, Brønsted and Lewis acid-modified supported ionic liquid catalysts were studied in one-pot synthesis of menthols from citral. It was reported that the use of acidic modifiers in supported ionic liquid catalyst enhanced the selectivity towards menthols [22]. Immobilization of enzyme lipase together with ionic liquid on active carbon was carried out. Supported enzyme ionic liquid catalyst was observed to be active and selective in the asymmetric acylation of 1-phenylethanol with vinyl acetate. Furthermore, it was observed that the presence of ionic liquid inhibited the catalyst deactivation during the reaction [23]. Ionic liquid 1-ethyl3-methylimidazolium chloride was applied as a solvent for pretreatment of forest and agricultural residue prior to the process of enzymatic hydrolysis. Enhancement in the synthesis of simple, mono- and disaccharides was observed after the pretreatment with ionic liquid. Hence, the concept of using ionic liquid as a solvent for pretreatment of woody biomass, prior to enzymatic hydrolysis, offers an interesting possibility for the production of bioethanol [24].

Ionic liquids can act as a dehydration agent and in water solutions HMF can easily be rehydrated [25]. In addition, sugar dehydration process involves complex reaction steps. Also, HMF can further be transformed, for example, to levulinic and formic acids. Ionic liquids can improve the selectivity towards HMF via suppressing the consecutive reactions such as formation of levulinic and formic acids, respectively [26]. One challenge upon production of HMF is the emergence of polymerization reactions leading to the formation of insoluble humins, particularly when more concentrated sugar solutions are used. On the other hand, relatively concentrated solutions should be used in order to make the processes economically feasible. To minimize the amounts of ionic liquids, they can either be used as cosolvents [13] or applied in an immobilized form as a new type of heterogeneous catalysts $[27,28]$.

Ionic liquid-assisted derivatizations of HMF have also been demonstrated. HMF is not an optimal internal combustion fuel due to its high boiling point. Both hydrogenolysis and hydrogenation of HMF to dimethylfuran (DMF) and esterification to corresponding esters have been demonstrated over supported noble metal catalysts in ionic liquids $[29,30]$. Both reaction products could be used as fuels or fuel additives [18].

Herein various sample biofuels and their properties (Section 2), dehydration of sugars and cellulose (Section 3), dehydration of lignocellulosic material in ionic liquids to HMF (Section 4) as well as hydrogenation/hydrolysis of 
HMF in ionic liquids [30] and transformation of sugars to HMF esters [18] (Section 5) are discussed.

\section{Petroleum and Diesel Alternatives}

Transportation sector is still dependent on liquid fuels, both in a range of gasoline and diesel. The most common gasoline type biofuel is bioethanol, which is produced via acid [9] or enzymatic hydrolysis [9] of biomass followed by fermentation. The drawbacks for this fuel are its water miscibility, low energy content $(23 \mathrm{MJ} / \mathrm{L})[31,32]$ in comparison to gasoline (35 MJ/L) [32], and low boiling point. Moreover, corrosion problems, poor engine cold-start performance, and reduced distance range per tank are all the result of the use of alcohol-gasoline fuel blends. Still, today catalytic converters in Otto motor vehicles are designed to tackle the emissions from burning of gasoline hydrocarbon mixtures and, consequently, when used in the cars burning ethanol mixtures, toxic acetaldehyde can be formed [33]. This can also potentially lead to increasing problems with photochemical smog [34]. Furthermore ethanol is often produced from edible sources, originating particularly from sugar cane, although efforts towards the lignocellulosic bioethanol production are ongoing. In fact, for example, the Örnsköldsvik biorefinery cluster [35] produces even today significant amounts of cellulosic ethanol thanks to the finetuned, acidic, sulphite pulping method they use [36].

Interestingly, ethanol can also serve as a feedstock for other valuable products. One possible candidate which can also be used as a biofuel is 1-butanol that can be manufactured from ethanol by applying modern chemical technology. This type of reactions has been demonstrated over heterogeneous catalysts in the continuous operating mode [37-42]. One interest among this type of technology is that it can be carried out by a simple one-pot synthesis strategy. The real advantage is gained in energy savings and easy operation procedures. The reason for seeking ethanol replacement with butanol is based on the fact that butyl alcohol has better physicochemical properties than ethanol and consequently, is suitable to be used as a fuel in traditional gasoline engines [43]. For instance, the energy content of butanol $(29 \mathrm{MJ} / \mathrm{L})$ is higher than that of ethanol. Butanol can be used in higher blends with gasoline compared to ethanol and it is safe due to low evaporation tendency [43]. Moreover, 1-butanol is only slightly miscible with water which allows the delivery of it by taking advantage of existing pipelines and storage tanks, which is not the case with ethyl alcohol. Consequently, it is not surprising that several companies (e.g., DuPont, BP) have concentrated research efforts on sustainable 1-butanol production. Looking back to the history, the first reports on the industrial scale production of 1-butanol were presented in 1912-1914, which were based on ABE fermentation process [44]. During that time, fermentation was based on bacterium Clostridia acetobutylicum. The outcome was a mixture of ABE (acetone, butanol, and ethanol). Later on, the production was shifted towards fossil-based resources resulting in development of the oxo-process that uses propylene as a feedstock [45].
In terms of sustainability, the old microorganism-based production technology has gained a lot of attention and, thus, modern studies have reported interesting results in this area [43-47]. In conclusion, biobutanol can be straight manufactured from sugar containing material or by means of modern chemical reactor technology with ethyl alcohol as an intermediate.

Several biomass utilizing production technologies exist for liquid biofuels in the diesel range. Sample technologies comprise of hydrotreatment [48], hydrodeoxygenation [49], catalytic deoxygenation, and transesterification of triglycerides to diesel-like biofuels $[50,51]$. Unfortunately, the raw materials used are frequently edible or occupy land needed for the cultivation of food. The benefit of diesellike fuel is that it has chemically similar structure as the current petroleum-based diesel, whereas FAME contains oxygen. Producing diesel range biofuel from lignocellulose and agricultural waste is ethically more mature than to use edible resources in fuel production.

5-hydroxymethyl furfural can be produced from sugars and lignocelluloses via dissolution and dehydration (see Sections 3 and 4). Nevertheless, it is an intermediate, having a boiling point too high $\left(179^{\circ} \mathrm{C}\right)$ to be used directly as a transportation fuel. Thus, it should be derivatized to other compounds, such as furan derivatives, particularly dimethylfuran (DMF), which is a suitable compound for gasoline-range fuel [52]. The boiling point of DMF is 92$94^{\circ} \mathrm{C}$ and its energy density is $31.5 \mathrm{MJ} / \mathrm{L}[31,32]$. DMF can be produced by hydrogenolysis/hydrogenation of HMF [48].

5-hydroxymethyl furfural can also be transformed to diesel-type fuels [48]. HMF esters [18, 53] have been proven to be suitable fuel or fuel-additive candidates, like 5-ethoxymethylfurfural (EMF) $[18,54]$. HMF esters are considered as relatively stable [18] and, consequently can be used as such or further derivatized.

\section{Ionic Liquids in the Dehydration of Sugars and Cellulose}

Ionic liquids are a subclass of molten salt materials that can be applied as solvents for species which are challenging to be dissolved in classical, molecular solvents. Some ionic liquids, for example $\left[\mathrm{C}_{4} \mathrm{MIM}\right][\mathrm{Cl}]$ and $\left[\mathrm{C}_{2} \mathrm{MIM}\right][\mathrm{Cl}]$ with high hydrogen bond basicity, have been found as efficient solvents and depolymerization agents for cellulose [55] to produce sugars. Consequently, they have also been applied in the dehydration of biomass to HMF [56]. Ionic liquids have certain benefits when applied as solvents in the production of HMF: for example, due to their relatively high viscosity, the further side reactions of HMF can be suppressed in ionic liquids [27].

Challenges of using ionic liquids in large-scale applications include drawbacks such as frequently encountered (and unknown) toxicity as well as difficult separation and reuse. Ecotoxicological evaluation of $\left[\mathrm{C}_{2} \mathrm{MIM}\right][\mathrm{Cl}]$ and some other ionic liquids has been performed [57]. One possibility to reduce the amount of ionic liquid needed is to apply it in an immobilized form, in line with the so-called "SILCA" 


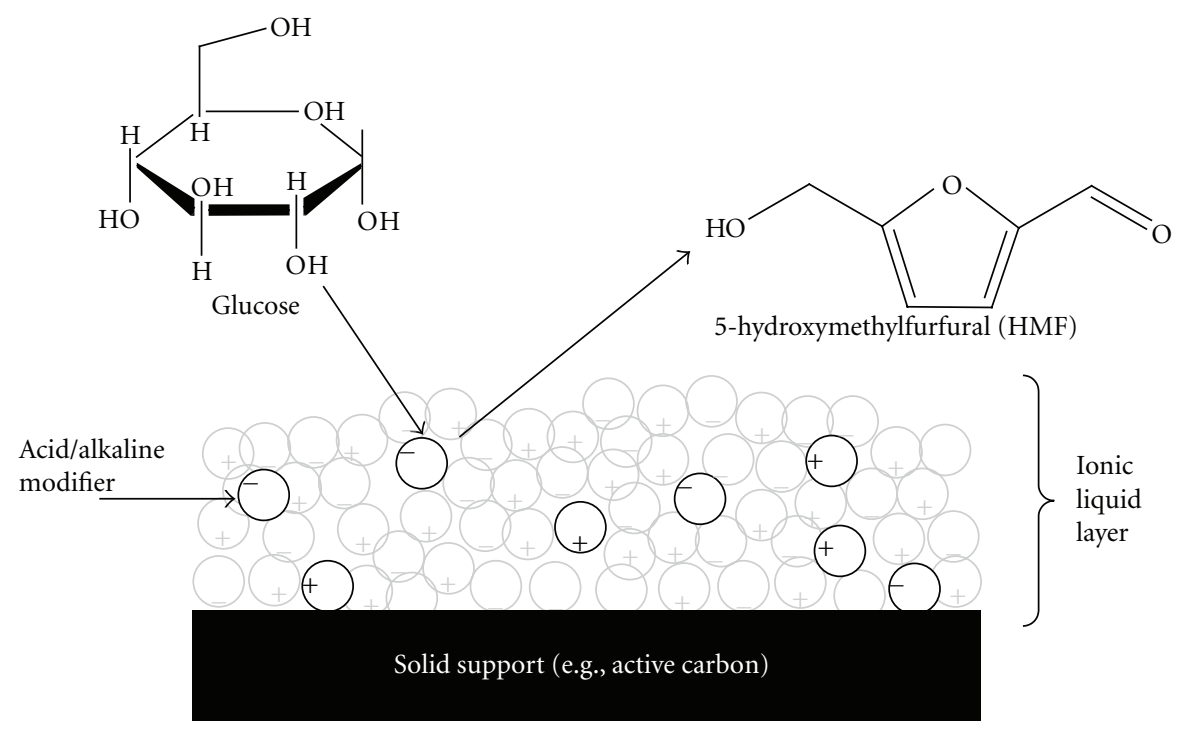

FIGURE 1: The structure of supported ionic liquid catalyst used in the dehydration of glucose to HMF, adapted from [28].

(Supported Ionic Liquid Catalyst) concept. The benefits of this concept are an easy catalyst separation and reuse. The authors have been developing the SILCA concept and applied it successfully in hydrogenation of unsaturated aldehydes and dehydration of glucose $[22,28]$.

3.1. Dehydration of Sugars. The easiest dehydration of sugars to HMF occurs for fructose, a pentose readily available in multiton scale. When the starting material is glucose, a cheaper sugar than fructose [13], an isomerization (epimerization) step from glucose to fructose is needed prior to the acid catalyzed dehydration. Efficient isomerization catalysts are, for example, $\mathrm{CrCl}_{3}$ and $\mathrm{CrCl}_{2}$ [13]. Glucose isomerization to fructose has been proposed to proceed via enediolate intermediate with the latter catalyst, when the glucose ring is opened and two of its oxygen species are interacting with a hexa-coordinated chromium(II) complex [13].

3.1.1. Homogeneous Catalysis. The best yields of HMF from glucose and fructose are achieved with homogeneous ionic liquid catalyst systems where ionic liquid is either catalyst or solvent $[17,56,58]$. Glucose has been efficiently converted to HMF in a homogeneous ionic liquid catalyst system containing Lewis acids (metal chlorides), whereas acidic ionic liquids have demonstrated to efficiently dehydrate fructose $[56,58]$.

3.1.2. Supported Ionic Liquid Catalysis. Supported ionic liquid catalysts consist of a catalytically active species residing in a thin layer of ionic liquid which is immobilized on a solid support material. The catalytically active species can be, for example, solid metal nanoparticles, homogeneous catalyst (metal complexes) in ionic liquid or, for example, enzymes in ionic liquid $[23,59,60]$. These kind of catalysts are mentioned with different terms in scientific literature, such as SILCA [59], SCILL (supported catalyst with ionic liquid layer) [61], SCIL (supported catalyst with ionic liquid) [62], or SILPC (supported ionic liquid phase catalyst) [63].

The ionic liquid acts as a reaction environment and it can have a positive influence on the chemical properties of the catalysts. By varying ionic liquids, it is possible to influence the concentrations of compounds and intermediates on the surface of the solid catalyst [60].

Immobilization of ionic liquids can be achieved by different techniques, such as simple impregnation, grafting, solgel method, or polymerization [59,63-65]. The catalyst that contains an ionic modifier (Lewis acid modifier or alkaline modifier) in an ionic liquid layer immobilized on a solid support has been successfully used in glucose dehydration reactions (Figure 1) [28].

Open literature introduces one example of fructose dehydration taking advantage of an immobilized ionic liquid catalyst. The use of 1-triethoxy(silylpropyl)-3-methylimidazolium hydrogen sulfate ionic liquid supported on silica nanoparticles was demonstrated to act as a catalyst in fructose dehydration (Figure 2) [27]. Maximally, 63\% yield of HMF was achieved at close to complete conversion of fructose at $150^{\circ} \mathrm{C}$. The bulk solvent used was DMSO. Further, the catalyst used in the reaction at $130^{\circ} \mathrm{C}$ could be reused in seven consecutive experiments.

3.2. Dehydration of Cellulose. The dehydration reaction becomes more complex when the starting material is cellulose or lignocellulose, since both dissolution of the raw material and its hydrolysis must occur in order to obtain sugars. For this purpose, both ionic liquids, (such as $\left[\mathrm{C}_{4} \mathrm{MIM}\right][\mathrm{Cl}]$ and $\left[\mathrm{C}_{2} \mathrm{MIM}\right][\mathrm{Cl}]$ ) and conventional solvents (e.g., N,Ndimethylacetamide (DMA-LiCl)) have been used (Figure 3). One challenge in the utilization of ionic liquids is often their high price. Thus, reuse of ionic liquids or their use as a cosolvents represent viable means of cost reduction [13]. 


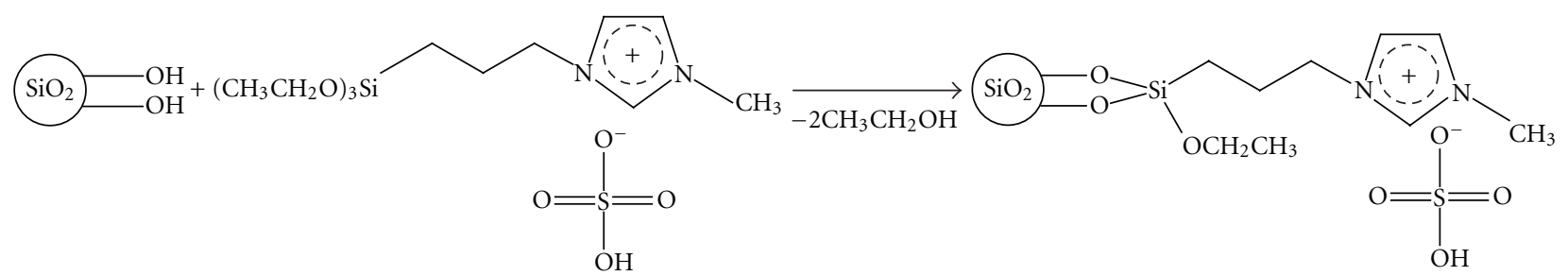

FIGURE 2: Schematic illustration describing the synthesis of 1-triethoxy(silylpropyl)-3-methyl-imidazolium hydrogen sulfate supported on silica, adapted from [27].



(a)



(b)



(c)

FIGURE 3: Examples of powerful solvents for lignocellulosic biomass: (a) DMA-LiCl, (b) 1-ethyl-3-methylimidazolium chloride $\left[\mathrm{C}_{2} \mathrm{MIM}\right][\mathrm{Cl}]$, (c) 1-butyl-3-methylimidazolium chloride $\left[\mathrm{C}_{4} \mathrm{MIM}\right][\mathrm{Cl}]$.

When DMA-LiCl was used as a solvent for cellulose, the role of the addition of $\left[\mathrm{C}_{2} \mathrm{MIM}\right][\mathrm{Cl}]$ was to promote the dissolution of cellulose via bringing more lose chloride groups into the system, that, consequently, were proposed to interact with the hydroxyl groups of cellulose [13]. Furthermore, the system became less viscous when the ionic liquid was diluted with another solvent.

\section{Synthesis of 5-Hydroxymethylfurfural from Lignocellulosic Materials}

Only a few publications dealing with the synthesis of HMF directly from lignocellulosic biomass can be found $[11,13]$. The raw materials investigated were corn stover [13], wheat [12] and rice straw [11], corn stalk [11], and pine wood [11]. Agricultural waste, such as wheat and rice straw, corn stalk, and stover, all contain different amounts of cellulose, hemicelluloses, and lignin. For example, wheat straw contains $42 \mathrm{wt}-\%$ cellulose and $26 \mathrm{wt}-\%$ hemicelluloses [66], whereas rice straw contains only $32 \mathrm{wt}-\%$ cellulose in addition to $24 \mathrm{wt}-\%$ hemicelluloses and $13 \mathrm{wt}$ \% lignin [67]. Corn stalk contains about $3 \mathrm{wt}-\%$ lignin but is rich in cellulose and hemicelluloses (29wt-\% and $28 \mathrm{wt}-\%$, resp.) [68]. Corn stover contains $34 \mathrm{wt}-\%$ cellulose, whereas cellulose content of pine sawdust is around $40 \mathrm{wt}-\%$ [15]. Thus, due to their lower cellulose content, it is expected that corn stover and stalk are easier to convert to HMF than pine or wheat straw.

One-pot synthesis of HMF, starting from $10 \mathrm{wt}-\%$ corn stover, in N,N-dimethylacetamide and $10 \mathrm{wt}-\% \mathrm{LiCl}$ has been demonstrated [13]. The catalytic system contained $10 \mathrm{~mol}-$ $\%$ of $\mathrm{CrCl}_{3}$ coupled with [ $\left.\mathrm{C}_{2} \mathrm{MIM}\right][\mathrm{Cl}]$, and $10 \mathrm{~mol}-\%$ of $\mathrm{HCl}$. The temperature was $140^{\circ} \mathrm{C}$, at which conditions the reaction took 5 hours to be completed. The maximum yield of HMF was 48 mol- $\%$ since also 34 mol-\% of furfural was obtained starting from xylan [13]. The authors' assessment was that, in this system, the role of chloride ions was to form hydrogen bonds between hydroxyl groups of cellulose thus enabling the disruption of its inter- and intramolecular hydrogen bonds. However, other opinions exist about how ionic liquids are dissolving cellulose. In essence, it was proposed that small ions capable of hydrogen bonding as well as the delocalization ability of the positive charge within the cation of ionic liquids can assist in the dissolution process [69]. In a recent publication [70], hydrogen-bonding basic media (ionic liquids) were observed to break intra- and intermolecular hydrogen bonds in crystalline cellulose.

Chromium in $\mathrm{CrCl}_{3}$ catalyzes the isomerization of glucose to fructose, which is an intermediate step in the formation of hydroxymethylfurfural [56]. High HMF yield, on the level of furfural, can be obtained in the industrial process starting from hemicelluloses [71]. The yields of HMF and furfural, respectively, from rice straw were $47 \%$ and $23 \%$ when $\left[\mathrm{C}_{4} \mathrm{MIM}\right][\mathrm{Cl}]$ and $\mathrm{CrCl}_{3}$ as a precatalyst were used under microwave heating, for $3 \mathrm{~h}$. In reality, the $\mathrm{CrCl}_{3}$ and the anion, $\mathrm{Cl}^{-}$, interact upon which a complex equilibria of mixed chromium chloride anions are formed. In addition, very similar yields were achieved with corn stalk as the raw material resulting in HMF and furfural yields of $45 \%$ and $23 \%$, respectively [11]. Further, upon transformation of pine wood, the highest yield of HMF (52\%) was achieved under microwave heating for $3 \mathrm{~h}$ in $\left[\mathrm{C}_{4} \mathrm{MIM}\right][\mathrm{Cl}]$ using $\mathrm{CrCl}_{3}$ as the catalyst [11]. At the same time, 31\% of furfural was produced. The furfural yield was lower than expected and performing an additional experiment with furfural in a microwave oven revealed that it partially degrades to humins under microwave conditions. On the other hand, only about 


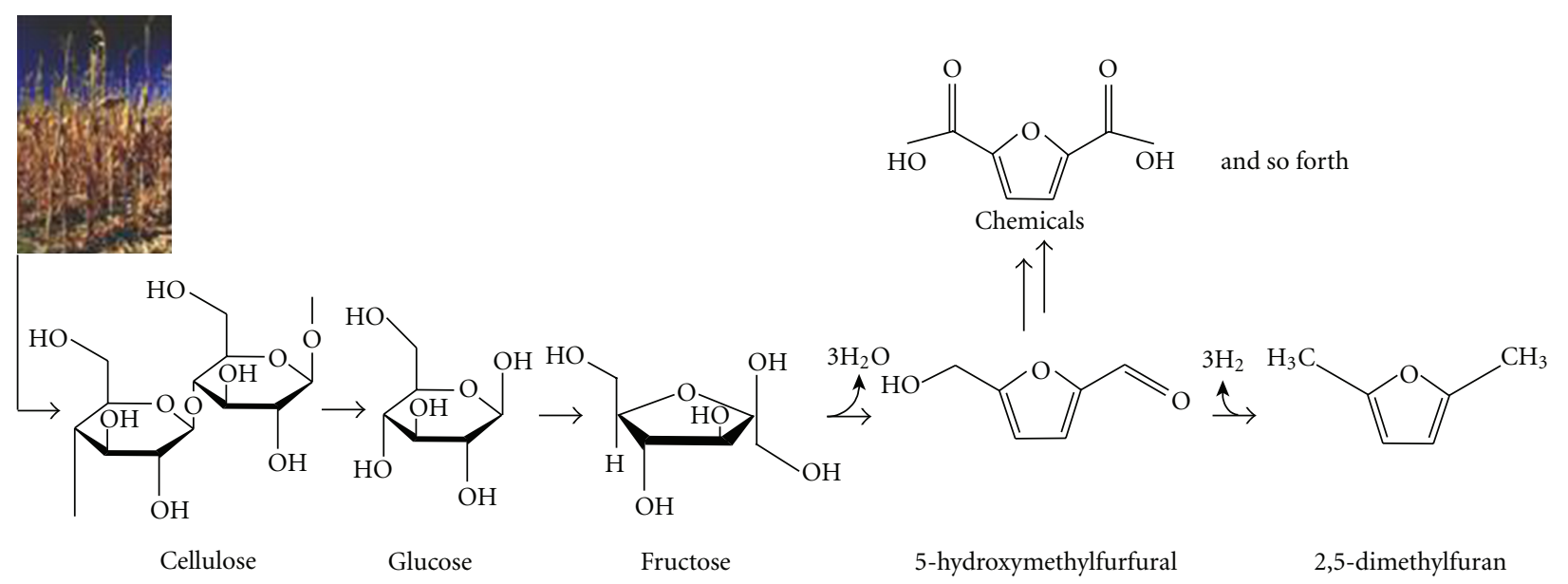

FIGURE 4: A Simplified reaction scheme for the synthesis of HMF and DMF from biomass, adapted from [13].

$19 \%$ yield of $\mathrm{HMF}$ was achieved from pine sawdust, at $140^{\circ} \mathrm{C}$ and $5 \mathrm{~h}$, when using $33 \mathrm{~mol}-\% \mathrm{CrCl}_{3}$ as a catalyst in $15 \mathrm{wt}-$ $\%\left[\mathrm{C}_{2} \mathrm{MIM}\right][\mathrm{Cl}]$. The lower HMF yield, compared to that achieved for corn stover (see above), can be explained by the higher cellulose content in the former one. Unfortunately, no direct comparative results for the transformation of corn stover were available. The results were, however, promising since it was stated that lignin or proteins in biomass did not interfere with the process. Any residual fractions could at least be burnt to energy, in order to improve the overall economy of the process. On the other hand, the toxicity and relatively high amount of chromium are still challenging when considering any potential large-scale application. Furthermore, after neutralization of the supernatant reaction mixture containing HMF, it could be hydrogenolyzed and hydrogenated in the second step to DMF. In this demonstration, ionic liquid was not used as a solvent, although principally it could be used (see Section 5). For improved feasibility, the solvent and ionic liquid recycling issues still need to be resolved.

\section{Synthesis of HMF Derivatives in Ionic Liquids}

As already discussed, pure HMF is not directly suited as a fuel (see Section 2). Therefore, various HMF transformations have been introduced. Hydrogenolysis [30] and esterification [18] are representative examples.

5.1. Synthesis of Dimethylfuran. Various supported noble metal catalysts were applied in the hydrogenolysis of HMF. Since these catalysts are easily poisoned by acids used in the dehydration step in HMF synthesis, a neutralization step is needed. Thus, a two-step method for the production of DMF from glucose has been proposed (Figure 4) [30]. Initially, as a result of glucose dehydration, hydroxymethylfurfural was obtained when 12-molybdophosphoric acid $\left(\mathrm{H}_{3} \mathrm{PMo}_{12} \mathrm{O}_{40}\right)$ was applied as the catalyst in a $\left[\mathrm{C}_{2} \mathrm{MIM}\right][\mathrm{Cl}]$ ionic liquidacetonitrile dual-solvent system. 90 mol-\% HMF selectivity, at $66 \mathrm{~mol}-\%$ glucose conversion was achieved at $120^{\circ} \mathrm{C}$ and $3 \mathrm{~h}$. As the second step, hydrogenation and hydrogenolysis of hydroxymethylfurfural were performed over Pd/C catalysts. Prior to the second step, the reaction mixture was cooled down to $50^{\circ} \mathrm{C}$ and neutralized with sodium carbonate. The salt, $\mathrm{Na}_{3} \mathrm{PMo}_{12} \mathrm{O}_{40}$, together with the humins were centrifuged and the supernatant containing HMF was loaded into an autoclave. Palladium on active carbon (Pd/C) was applied as a catalyst in the hydrogenation/hydrolysis. Furthermore, the hydrogenation reaction of intermediates from HMF, such as methylfuran (MF), 5-methylfurfural alcohol (MFA), and 2,5-dihydroxymethylfuran (DHMF) was separately studied (Figure 5). In this way it was possible to determine the comparative rates of each step. The reactions were performed under 62 bars of hydrogen, at $120^{\circ} \mathrm{C}$, using $50: 1$ reactant-tometal ratio. Furthermore, the initial amount of the reactant was $1 \mathrm{mmol}$ in $46 \mathrm{mmol}$ of the mixture. Thus, the complete procedure comprises of dehydration, neutralization, and separation of solids, followed by hydrogenation and hydrogenolysis. Still, the recycling issues for both the ionic liquid as well as the catalyst should be resolved.

It was revealed from the mechanistic studies that DHMF acts as an inhibitor upon formation of MFA. MF was the main product after 60 min reaction time (selectivity 36\%, at $47 \%$ conversion HMF). The corresponding selectivity to DMF was $32 \%$. Furthermore, DMHF and MFA rapidly dehydrate and could only be found in the reaction mixture in minor amounts.

5.2. Esterification of HMF. One-pot synthesis, combining the sugars-to-HMF and HMF esterification steps, has been reported to occur in ionic liquids. In these cases ionic liquids act either as inert solvents or as both solvent and acid catalyst, in combination with $\mathrm{CrCl}_{3}$ as an isomerization catalyst [18].

Esterification of HMF with propionic acid has been studied both starting from glucose and fructose as a reactant. At relatively mild reaction conditions $\left(100^{\circ} \mathrm{C}\right)$, both pure 1-ethyl-3-methylimidazolium chloride and its mixture with 3-methylimidazolium bis(trifluoromethanesulfonyl)imide were applied as solvent. Although, the latter ionic liquid is not an excellent solvent for carbohydrates, it helps to lower the viscosity of the solution in contrast to the system 




FIGURE 5: The proposed reaction network for HMF hydrogenation/hydrogenolysis over $\mathrm{Pd} / \mathrm{C}$ in $\left[\mathrm{C}_{2} \mathrm{MIM}\right][\mathrm{Cl}]-$ acetonitrile dual solvent system [29]. Abbreviations: HMF: 5-hydroxymethylfurfural, MF: methylfuran, MFA: 5-methylfurfural alcohol, DHMF: 2,5dihydroxymethylfuran, OMBM: 5,5'-(oxybis(ethylene))bis(2-methylfuran), DMF: 2,5-dimethylfuran, MTHFA: 5-methyltetrahydrofurfuryl alcohol, AL: algelica lactone, HD: 2,5-hexanedione.<smiles>CC[n+]1ccn(C)c1</smiles><smiles>CC(=O)OCc1ccc(C=O)o1</smiles>

AMF<smiles>C[n+]1cc[nH]c1</smiles>

$[\mathrm{HMIM}]\left[\mathrm{NTf}_{2}\right]$<smiles>CCC(=O)OCc1ccc(C=O)o1</smiles>

PMF

Figure 6: Ionic liquids, 1-ethyl-3-methylimidazolium chloride [ $\left.\mathrm{C}_{2} \mathrm{MIM}\right][\mathrm{Cl}]$, and $\mathrm{H}$-3-methylimidazolium bis(trifluoromethanesulfonyl)imide [HMIM] $\left[\mathrm{NTf}_{2}\right]$ in the synthesis of 5-(propionyloxy)methyl furfural (PMF) and 5-acetoxy methyl furfural (AMF).

containing only the former ionic liquid. Much higher yields of HMF ( 49 mol-\%) and some 5-(propionyloxy)methyl furfural (PMF) (3 mol-\%) were achieved after $3 \mathrm{~h}$ under the same reaction conditions when starting from fructose instead of glucose (Figure 6). The reason is clear: when starting from fructose, no isomerization (epimerization) step is required.

In the esterification of HMF originating from either fructose or glucose, with acetic acid, very high yield of 5-acetoxymethyl furfural (AMF) was achieved $(75 \mathrm{~mol}-\%$ in $3 \mathrm{~h}$ reaction time). At the same time, about $20 \mathrm{~mol} \%$ of HMF was present in the reaction mixture without its further esterification. On the other hand, if the isomerization step is needed, the corresponding yields of AMF and HMF were only 9 mol- $\%$ and 2 mol- $\%$, respectively.

\section{Conclusions}

There is a clear call to develop new technologies aiming at especially liquid biofuels suitable as transportation fuels. Bioethanol is today produced in large scale, but due to its poor qualities in comparison with, for example, gasoline, new processes aiming at upgraded transportation fuels are needed. 
In addition, also other liquid biofuels based on vegetable oils and lignocellulosic biomass have been developed. The main drawback upon the use of several raw materials, particularly vegetable oils, is their competition with the food supply. Thus, lignocellulosic biomass should be the favoured as a raw material for liquid biofuels of future.

Ionic liquid- assisted sugar dehydration, starting either from fructose or glucose, has been intensively reported in literature. Besides efficient dehydration and solubilization capability, also isomerization functionality is needed for hexoses.

One-pot synthesis of HMF directly from biomass in ionic liquid systems has been successfully demonstrated. The best molar yields of HMF obtained from corn stover so far reached $48 \%$. In the case of microwave heating and pine wood as a raw material, slightly higher HMF yield (52\%) could be achieved. The plausible reason for this is the efficient heating of ionic liquids in a microwave field resulting in a more complete transformation of biomass.

The various HMF-derivatives open up an avenue for next-generation transportation fuels. Besides various esters and ethers, dimethylfurfural, a hydrogenation product of $\mathrm{HMF}$, is of interest, since it is directly applicable in transportation fuel applications.

\section{Acknowledgments}

This work is part of the activities at the Åbo Akademi University Process Chemistry Centre within the Finnish Centre of Excellence Programs (2000-2011) appointed by the Academy of Finland. Academy of Finland is gratefully acknowledged for financial support. In Sweden, the Bio4Energy program is acknowledged.

\section{References}

[1] F. Birol, World Energy Outlook 2010, International Energy Agency, Paris, France, 2010.

[2] G. Centi, P. Lanzafame, and S. Perathoner, "Analysis of the alternative routes in the catalytic transformation of lignocellulosic materials," Catalysis Today, vol. 167, pp. 14-30, 2011.

[3] IEA, World Energy Outlook 2009, International Energy Agency, Paris, France, 2009.

[4] J. Goettemoeller and A. Goettemoeller, "The history of vegetable oil based diesel fuels," in The Biodiesel Handbook, G. Knothe, Ed., chapter 2, 2007.

[5] J. Goettemoeller and A. Goettemoeller, Sustainable Ethanol: Biofuels, Biorefineries, Cellulosic Biomass, Flex-Fuel Vehicles, and Sustainable Farming for Energy Independence, Prairie Oak Publishing, Maryville, Mo, USA, 2007.

[6] http://www.preem.se/default_-__2973.aspx.

[7] http://www.sunpine.se/.

[8] http://www.nesteoil.fi/.

[9] P. Mäki-Arvela, T. Salmi, B. Holmbom, S. Willför, and D. Y. Murzin, "Synthesis of sugars by hydrolysis of hemicellulosesA review," Chemical Reviews, vol. 111, no. 9, pp. 5638-5666, 2011.

[10] P. Mäki-Arvela, I. Anugwom, P. Virtanen, R. Sjöholm, and J. P. Mikkola, "Dissolution of lignocellulosic materials and its constituents using ionic liquids-A review," Industrial Crops and Products, vol. 32, no. 3, pp. 175-201, 2010.

[11] Z. Zhang and Z. K. Zhao, "Microwave-assisted conversion of lignocellulosic biomass into furans in ionic liquid," Bioresource Technology, vol. 101, no. 3, pp. 1111-1114, 2010.

[12] P. Wang, H. Yu, S. Zhan, and S. Wang, "Catalytic hydrolysis of lignocellulosic biomass into 5-hydroxymethylfurfural in ionic liquid," Bioresource Technology, vol. 102, no. 5, pp. 4179-4183, 2011.

[13] J. B. Binder and R. T. Raines, "Simple chemical transformation of lignocellulosic biomass into furans for fuels and chemicals," Journal of the American Chemical Society, vol. 131, no. 5, pp. 1979-1985, 2009.

[14] M. E. Zakrzewska, E. Bogel-Łukasik, and R. Bogel-Łukasik, "Ionic liquid-mediated formation of 5-hydroxymethylfurfural-A promising biomass-derived building block," Chemical Reviews, vol. 111, no. 2, pp. 397-417, 2011.

[15] J. B. Binder and R. T. Raines, "Simple chemical transformation of lignocellulosic biomass into furans for fuels and chemicals," WO2009/155297 A1.

[16] A. Bruggink, R. Schoevaart, and T. Kieboom, "Concepts of nature in organic synthesis: cascade catalysis and multistep conversions in concert," Organic Process Research and Development, vol. 7, no. 5, pp. 622-640, 2003.

[17] C. Moreau, A. Finiels, and L. Vanoye, "Dehydration of fructose and sucrose into 5-hydroxymethylfurfural in the presence of 1H-3-methyl imidazolium chloride acting both as solvent and catalyst," Journal of Molecular Catalysis A, vol. 253, no. 1-2, pp. 165-169, 2006.

[18] G. Gruter, L. E. Manzer, A. S. V. De Sousa Dias, F. Dautzenberg, and J. Purmova, "Hydroxymethylfurfural ethers and esters prepared in ionic liquids," WO2009/030512.

[19] T. Ståhlberg, S. Rodriguez-Rodriguez, P. Fristrup, and A. Riisager, "Metal-free dehydration of glucose to 5-(Hydroxymethyl)furfural in ionic liquids with boric acid as a promoter," Chemistry, vol. 17, no. 5, pp. 1456-1464, 2011.

[20] J. P. Mikkola, P. Virtanen, and R. Sjöholm, "Aliquat 336-A versatile and affordable cation source for an entirely new family of hydrophobic ionic liquids," Green Chemistry, vol. 8, no. 3, pp. 250-255, 2006.

[21] P. Virtanen, J. P. Mikkola, E. Toukoniitty et al., "Supported ionic liquid catalysts-From batch to continuous operation in preparation of fine chemicals," Catalysis Today, vol. 147, pp. S144-S148, 2009.

[22] P. Virtanen, H. Karhu, G. Toth, K. Kordas, and J. P. Mikkola, "Towards one-pot synthesis of menthols from citral: modifying Supported Ionic Liquid Catalysts (SILCAs) with Lewis and Brønsted acids," Journal of Catalysis, vol. 263, no. 2, pp. 209219, 2009.

[23] P. Hara, J. P. Mikkola, D. Y. Murzin, and L. T. Kanerva, "Supported ionic liquids in Burkholderia cepacia lipase-catalyzed asymmetric acylation," Journal of Molecular Catalysis B, vol. 67, no. 1-2, pp. 129-134, 2010.

[24] R. Pezoa, V. Cortinez, S. Hyvärinen et al., "Use of ionic liquids in the pretreatment of forest and agricultural residues for the production of bioethanol," Cellulose Chemistry and Technology, vol. 44, no. 4-6, pp. 165-172, 2010.

[25] B. F. M. Kuster, "5-hydroxymethylfurfural (HMF). A review focusing on its manufacture," Starch/Stärke, vol. 42, pp. 314321, 1990.

[26] C. Li, Z. K. Zhao, A. Wang, M. Zheng, and T. Zhang, "Production of 5-hydroxymethylfurfural in ionic liquids under high 
fructose concentration conditions," Carbohydrate Research, vol. 345, no. 13, pp. 1846-1850, 2010.

[27] K. B. Sidhpuria, A. L. Daniel-Da-Silva, T. Trindade, and J. A. P. Coutinho, "Supported ionic liquid silica nanoparticles (SIL$\mathrm{nPs}$ ) as an efficient and recyclable heterogeneous catalyst for the dehydration of fructose to 5-hydroxymethylfurfural," Green Chemistry, vol. 13, no. 2, pp. 340-349, 2011.

[28] E. Salminen, P. Virtanen, P. Mäki-Arvela, N. Kumar, and J.-P. Mikkola, "Synthesis of 5-hydroxymethylfurfural (HMF) over acid/alkaline modified supported ionic liquid catalysts," in Proceedings of the International Congress on Renewable Energy (ICORE '11), S. K. Samdarshi, S. Mahapatra, and S. Paul, Eds., Assam, India, 2011.

[29] J. A. Dumesic, Y. Roman-Leshkov, and J. N. Chheda, "Catalytic process for producing furan derivatives in a biphasic reactor," US Patent no. 7572925 B2, 2009.

[30] M. Chidambaram and A. T. Bell, "A two-step approach for the catalytic conversion of glucose to 2,5-dimethylfuran in ionic liquids," Green Chemistry, vol. 12, no. 7, pp. 1253-1262, 2010.

[31] J. Lewkowski, "Synthesis, chemistry and applications of 5hydroxymethyl-furfural and its derivatives," Arkivoc, vol. 2001, no. 1, pp. 17-54, 2001.

[32] Y. Román-Leshkov, C. J. Barrett, Z. Y. Liu, and J. A. Dumesic, "Production of dimethylfuran for liquid fuels from biomassderived carbohydrates," Nature, vol. 447, no. 7147, pp. 982985, 2007.

[33] L. G. Anderson, "Ethanol fuel use in Brazil: air quality impacts," Energy and Environmental Science, vol. 2, no. 10, pp. 1015-1037, 2009.

[34] R. L. Tanner, "Atmospheric chemistry of aldehydes: enhanced peroxyacetyl nitrate formation from ethanol-fueled vehicular emissions," Environmental Science and Technology, vol. 22, no. 9, pp. 1026-1034, 1988.

[35] http://www.bioraffinaderi.se/.

[36] E. Sjöström, Wood Chemistry, Fundamentals and Applications, Academic press, London, UK, 2nd edition, 1993.

[37] T. Tsuchida, S. Sakuma, T. Takeguchi, and W. Ueda, "Direct synthesis of n-butanol from ethanol over nonstoichiometric hydroxyapatite," Industrial and Engineering Chemistry Research, vol. 45, no. 25, pp. 8634-8642, 2006.

[38] T. Tsuchida, J. Kubo, T. Yoshioka, S. Sakuma, T. Takeguchi, and W. Ueda, "Reaction of ethanol over hydroxyapatite affected by $\mathrm{Ca} / \mathrm{P}$ ratio of catalyst," Journal of Catalysis, vol. 259, no. 2, pp. 183-189, 2008.

[39] K. W. Yang, X. Z. Jiang, and W. C. Zhang, “One-step synthesis of n-butanol from ethanol condensation over alumina-supported metal catalysts," Chinese Chemical Letters, vol. 15, no. 12, pp. 1497-1500, 2004.

[40] I. C. Marcu, D. Tichit, F. Fajula, and N. Tanchoux, "Catalytic valorization of bioethanol over $\mathrm{Cu}-\mathrm{Mg}-\mathrm{Al}$ mixed oxide catalysts," Catalysis Today, vol. 147, no. 3-4, pp. 231-238, 2009.

[41] A. S. Ndou, N. Plint, and N. J. Coville, "Dimerisation of ethanol to butanol over solid-base catalysts," Applied Catalysis A, vol. 251, no. 2, pp. 337-345, 2003.

[42] C. Yang and Z. Y. Meng, "Bimolecular condensation of ethanol to 1-butanol catalyzed by alkali cation zeolites," Journal of $\mathrm{Ca}$ talysis, vol. 142, no. 1, pp. 37-44, 1993.

[43] L. A. Ashkinazi, "Biobutanol: biofuel of second generation," Economics of Chemical Industry, vol. 81, no. 12, pp. 2232-2236, 2008.

[44] M. Kumar and K. Gayen, "Developments in biobutanol production: new insights," Applied Energy, vol. 88, no. 6, pp. 1999-2012, 2011.
[45] H. P. Blaschek, "Bioproduction of butanol from biomass: from genes to bioreactors," Current Opinion in Biotechnology, vol. 18, no. 3, pp. 220-227, 2007.

[46] P. H. Pfromm, V. Amanor-Boadu, R. Nelson, P. Vadlani, and R. Madl, "Bio-butanol vs. bio-ethanol: a technical and economic assessment for corn and switchgrass fermented by yeast or Clostridium acetobutylicum," Biomass and Bioenergy, vol. 34, no. 4, pp. 515-524, 2010.

[47] J. Swana, Y. Yang, M. Behnam, and R. Thompson, "An analysis of net energy production and feedstock availability for biobutanol and bioethanol," Bioresource Technology, vol. 102, no. 2, pp. 2112-2117, 2011.

[48] H. Fukuda, A. Kondo, and H. Noda, "Biodiesel fuel production by transesterification of oils," Journal of Bioscience and Bioengineering, vol. 92, no. 5, pp. 405-416, 2001.

[49] J. R. Gomes, "Vegetable oil hydroconversion process," US Patent no. 2006/0186020 A1, 2006.

[50] P. Priecel, D. Kubička, L. Čapek, Z. Bastl, and P. Ryšánek, “The role of $\mathrm{Ni}$ species in the deoxygenation of rapeseed oil over NiMo-alumina catalysts," Applied Catalysis A, vol. 397, no. 12, pp. 127-137, 2011.

[51] D. Yu. Murzin, I. Kubickova, M. Snåre, P. Mäki-Arvela, and J. Myllyoja, "Method for the manufacture of hydrocarbons," WO 2006075057, US Patent no. 7, 491,858, 2009.

[52] O. O. James, S. Maity, L. A. Usman et al., "Towards the conversion of carbohydrate biomass feedstocks to biofuels via hydroxylmethylfurfural," Energy and Environmental Science, vol. 3, no. 12, pp. 1833-1852, 2010.

[53] G. M. M. Gruter and F. Dautzenberg, "Method for the synthesis of 5-alkoxymethyl furfural ethers and their use," WO2007/104514 A2.

[54] A. J. Sanborn, "Processes for the preparation and purification of hydroxymethyl furaldehyde and derivatives," WO2006/ 063220.

[55] J. L. Anderson, J. Ding, T. Welton, and D. W. Armstrong, "Characterizing ionic liquids on the basis of multiple solvation interactions," Journal of the American Chemical Society, vol. 124, no. 47, pp. 14247-14254, 2002.

[56] H. Zhao, J. E. Holladay, H. Brown, and Z. C. Zhang, "Metal chlorides in ionic liquid solvents convert sugars to 5hydroxymethylfurfural," Science, vol. 316, no. 5831, pp. 15971600, 2007.

[57] F. Ilgen, D. Ott, D. Kralisch, C. Reil, A. Palmberger, and B. König, "Conversion of carbohydrates into 5-hydroxymethylfurfural in highly concentrated low melting mixtures," Green Chemistry, vol. 11, no. 12, pp. 1948-1954, 2009.

[58] Q. Bao, K. Qiao, D. Tomida, and C. Yokoyama, "Preparation of 5-hydroymethylfurfural by dehydration of fructose in the presence of acidic ionic liquid," Catalysis Communications, vol. 9, no. 6, pp. 1383-1388, 2008.

[59] J. P. Mikkola, P. Virtanen, H. Karhu, T. Salmi, and D. Y. Murzin, "Supported ionic liquids catalysts for fine chemicals: citral hydrogenation," Green Chemistry, vol. 8, no. 2, pp. 197-205, 2006.

[60] C. P. Mehnert, E. J. Mozeleski, and R. A. Cook, "Supported ionic liquid catalysis investigated for hydrogenation reactions," Chemical Communications, vol. 8, no. 24, pp. 3010-3011, 2002.

[61] U. Kernchen, B. Etzold, W. Korth, and A. Jess, "Solid catalyst ionic liquid layer (SCILL) - A new concept to improve selectivity illustrated by hydrogenation of cyclooctadiene," Chemical Engineering and Technology, vol. 30, no. 8, pp. 985994, 2007.

[62] Y. Gu, C. Ogawa, J. Kobayashi, Y. Mori, and S. Kobayashi, "A heterogeneous silica-supported scandium/ionic liquid catalyst 
system for organic reactions in water," Angewandte Chemie, vol. 45, no. 43, pp. 7217-7220, 2006.

[63] A. Riisager, R. Fehrmann, S. Flicker, R. Van Hal, M. Haumann, and P. Wasserscheid, "Very stable and highly regioselective supported ionic-liquid-phase (SILP) catalysis: continuousflow fixed-bed hydroformylation of propene," Angewandte Chemie, vol. 44, no. 5, pp. 815-819, 2005.

[64] M. H. Valkenberg, C. DeCastro, and W. F. Hölderich, "Immobilisation of ionic liquids on solid supports," Green Chemistry, vol. 4, no. 2, pp. 88-93, 2002.

[65] F. Shi, Q. Zhang, D. Li, and Y. Deng, "Silica-gel-confined ionic liquids: a new attempt for the development of supported nanoliquid catalysis," Chemistry A, vol. 11, no. 18, pp. 5279$5288,2005$.

[66] O. Bobleter, "Hydrothermal degradation and fractionation of saccharides and polysaccharides," in Polysaccharides, Structural Diversity and Functional Versatility, S. Dumitriu, Ed., Marcel Dekker, New York, NY, USA, 2nd edition, 2005.

[67] R. C. Kuhad and A. Singh, "Lignocellulose biotechnology. Current and future prospects," Critical Reviews in Biotechnology, vol. 13, no. 2, pp. 151-172, 1993.

[68] J. H. Sloneker, "Agricultural residues, including feedlot wastes," Biotechnology and Bioengineering Symposium, no. 6, pp. 235-250, 1976.

[69] A. Pinkert, K. N. Marsh, and S. Pang, "Reflections on the solubility of cellulose," Industrial and Engineering Chemistry Research, vol. 49, no. 22, pp. 11121-11130, 2010.

[70] A. W. T. King, J. Asikkala, I. Mutikainen, P. Järvi, and I. Kilpeläinen, "Distillable acid-base conjugate ionic liquids for cellulose dissolution and processing," Angewandte Chemie, vol. 50, no. 28, pp. 6301-6305, 2011.

[71] K. J. Zeitsch, The Chemistry and Technology of Furfural and Its Many by-Products, Elsevier Press, Amsterdam, Netherlands, 2000. 

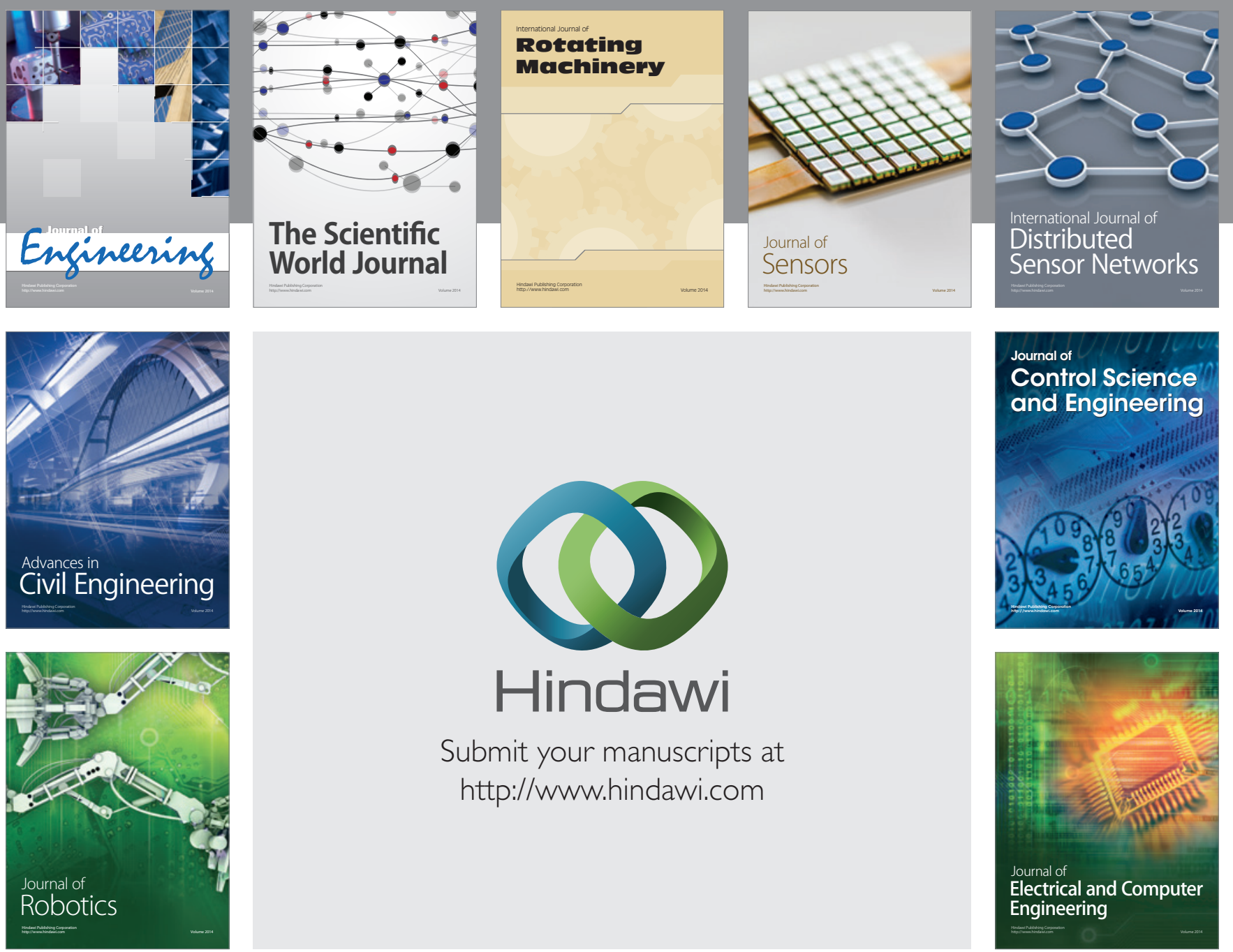

Submit your manuscripts at

http://www.hindawi.com
